\title{
Metabolic risk management, physical exercise and lifestyle counselling in low-active adults: controlled randomized trial (BELLUGAT)
}

Assumpta Ensenyat ${ }^{*}$ (D, Gemma Espigares-Tribo, Leonardo Machado, Francisco José Verdejo, Rosa Rodriguez-Arregui, José Serrano, Marta Miret, Gisela Galindo, Alfonso Blanco, Josep-Ramon Marsal, Susana Sarriegui, Xenia Sinfreu-Bergues and Noemi Serra-Paya

\begin{abstract}
Background: The primary aim of this study is to evaluate the effectiveness of different doses (intensity) of supervised exercise training - concomitant with lifestyle counselling - as a primary care intervention tool for the management of metabolic syndrome risk factors in low-active adults with one or more such factors (programme name in Catalan: Bellugat de CAP a peus).

Methods/Design: Three-arm, randomized controlled clinical trial implemented in the primary care setting, with a duration of 40 weeks (16 weeks intervention and 24-week follow-up).

Adults aged 30 to 55 years with metabolic risk factors will be randomized into three intervention groups: 1) aerobic interval training (16 supervised training lessons) plus a healthy lifestyle counselling programme (6 group and 3 individual meetings); 2) low-to-moderate intensity continuous training (16 supervised training lessons) plus the same counselling programme; or 3) the counselling- programme without any supervised physical exercise.

The main output variables assessed will be risk factors for metabolic syndrome (waist circumference, blood pressure, and levels of plasma triglycerides, high-density lipoproteins and glucose), systemic inflammation, cardiorespiratory fitness, physical activity and sedentary behaviour, dietary habits, health-related quality of life, self-efficacy and empowerment. Economic factors will also be analysed in order to determine the cost-effectiveness of the programme. These variables will be assessed three times during the study: at baseline, at the end of the intervention, and at followup. We estimate to recruit 35 participants per group.
\end{abstract}

Discussion: The results of this study will provide insight into the immediate and medium-term effects on metabolic risk and lifestyle of a combined approach involving aerobic interval training and a multidisciplinary behavioural intervention. If effective, the proposed intervention would provide both researchers and practitioners in this field with a platform on which to develop similar intervention programmes for tackling the repercussions of an unhealthy lifestyle.

Trial registration: Clinical trials.gov. NTC02832453. Registered 6 July 2016 (retrospectively registered).

\footnotetext{
* Correspondence: aensenat@inefc.udl.cat

Institut Nacional d'Educacio Fisica de Catalunya - Campus Lleida, Lleida,

Catalonia, Spain
} 


\section{Background}

Metabolic syndrome consists of a cluster of risk factors for cardiovascular disease that comprises abdominal obesity, impaired glucose tolerance, hypertension and dyslipidemia. When these factors appear together the cardiovascular risk rises substantially. In Spain, the prevalence of metabolic syndrome is $42.1 \%$ in men and $32.3 \%$ in women, and it increases with age [1].

A considerable body of epidemiological evidence indicates that the most prevalent diseases in developed societies, including metabolic syndrome, are closely linked to lifestyle factors, notably smoking, unhealthy dietary habits, physical inactivity and stress. The increasing prevalence of metabolic syndrome and its negative impact on individuals and society has been mainly attributed to a decline in regular physical activity, an increase in sedentary behaviour and changes in dietary habits. Given that these factors are all modifiable they may be reversed through interventions focussing on behavioural change. Changes in lifestyle can have a positively effect on the prevalence of cardiovascular risk factors and, therefore, on that of metabolic syndrome and cardiovascular diseases [2].

In an attempt to tackle the problem of unhealthy lifestyles, the World Health Organisation (WHO) developed a Global Strategy on Diet, Physical Activity and Health, the aim of which was to control and prevent noncommunicable diseases or their risk factors [3]. Physical activity has a key role to play in any such strategy. However, despite investment in the promotion of physical activity, the degree to which people engage in regular weekly exercise remains worryingly low. According to the Special Eurobarometer 412 [4], 54\% of European Union citizens interviewed had not, during the previous week, done any physical activity of vigorous intensity, and $44 \%$ had not done any exercise of moderate intensity. In addition to the lack of moderate-to-vigorous physical activity, about twothirds $(69 \%)$ of respondents also stated that they spent between 2.5 and $8.5 \mathrm{~h}$ sitting during waking hours, and 11\% sat for more than $8.5 \mathrm{~h}$.

The health benefits of regular physical exercise in terms of preventing and treating many non-communicable diseases are well-established [5]. They include positive effects on single metabolic risk factors, such as normalization of blood pressure and improvements in body composition, hyperlipidaemia and insulin resistance [5]. Physical exercise also increases cardiorespiratory and muscular fitness. Regarding metabolic syndrome as a whole, Pattyn and colleagues [6] recently conducted a meta-analysis and concluded that dynamic physical exercise has beneficial effects on the majority of metabolic risk factors (abdominal obesity, high-density lipoprotein cholesterol (HDLc), systolic and diastolic blood pressure), as well as on other factors such as body mass index (BMI) or maximal oxygen uptake $\left(\mathrm{VO}_{2 \max }\right)$. However, they also highlight that the most favourable modality/dose of exercise (dynamic versus static; low-to-moderate intensity versus high intensity) has yet to be fully elucidated.

Present guidelines for physical exercise as a healthy behaviour are based around continuous training methods (30-60 $\mathrm{min} /$ session, low-to-moderate intensity, 2-7 sessions per week) $[5,7,8]$. The WHO [9] recommends that individuals aged 18-65 should accumulate a minimum of 150 min per week of moderate-intensity physical activity or, alternatively, 75 min per week of vigorous physical activity, or a combination of both.

However, although moderate-intensity exercise is sufficient to reduce cardiovascular risk, it has been suggested that higher intensity exercise offers greater benefits [10-12]. Accordingly, the health setting has recently witnessed a growing interest in interval training methods, particularly high-intensity interval training (HIIT). When the aim of this method is to stimulate preferentially the aerobic system over the anaerobic one, it is referred to as aerobic interval training [13]. Aerobic interval training (AIT) consists of repeated bouts, either short $(<45 \mathrm{~s})$ or long ( 1 to $\left.8^{\prime}\right)$, of fairly high-intensity exercise (equal or superior to the maximal lactate steady-state velocity) interspersed with recovery periods.

To date, several studies have analysed the effects of AIT in individuals with cardiovascular risk factors or with diseases such as metabolic syndrome, ischaemic cardiopathy or cardiac insufficiency. Results from these studies suggest that AIT produces a greater improvement in $\mathrm{VO}_{2 \max }$ than does traditional continuous training (TCT). The effect has been described in recreationally active individuals [14], as well as in patients with coronary artery disease [15-17] or metabolic syndrome [18, 19]. It has also been shown that AIT reduces the prevalence of metabolic risk factors $[15,17,19,20]$. The positive effects of AIT on metabolic risk factors involve changes in body composition, ventricular and vascular functions, plasmatic adiponectin and glucose intolerance. Studies comparing the effects of different training methods generally report better results after AIT and suggest that this method optimizes the time necessary to induce muscular, metabolic and cardiorespiratory effects in the medium and long term $[17,19,20]$.

Although these studies support the efficacy of AIT for reducing metabolic risk factors, its effectiveness has yet to be fully demonstrated. One of the difficulties faced when seeking to replicate in practice the evidence obtained in controlled studies is that individuals are less constrained and become more responsible for their own compliance with physical exercise. As Rankin [10] states, physical exercise will have no benefits unless the individual actually does it. Accordingly, there is evidence to 
suggest that the most effective interventions, among those aiming to promote healthier behaviour, are those that not only involve scheduled physical activity and exercise but which also offer lifestyle counselling, including advice on dietary habits and how to reduce daily sedentary time, along with tools that can empower individuals towards behaviour change.

Detractors of high intensity exercise claim that HIT is not an appropriate or sustainable form of exercise for public heath guidelines because it is unlikely to induce changes in the population as a whole [21]. It is argued that HIIT will be associated with negative feelings and lack of enjoyment, leading therefore to poor compliance. Biddle, for example, claims that as a public health tool, higher intensity exercise may not be better if people are less willing to do it [21]. However, AIT is a form of HIIT in which exercise intensity is not maximal. This feature may explain why, contrary to what might be expected given the low physical condition of the participants in some studies, AIT sessions have been well tolerated by sedentary individuals with or without concomitant diseases [17, 19, 20, 22, 23]. Indeed, no adverse effects have been reported [10], even in patients with heart failure [12], because the intensity is tailored to the individual.

In addition, participants in AIT interventions report greater satisfaction than do people in TCT interventions. This could be attributable to the variable nature of the session, in comparison with the monotony of TCT sessions, as well as to the fact that the intensity of intervals promotes a greater sense of challenge. These aspects reflect the potential of AIT to improve adherence to exercise interventions [23]. Although in some individuals AIT may trigger a feeling of displeasure and, hence, impair their confidence and adherence [21], factors such as the optimization of time spent on training sessions and the associated satisfaction of participants may contribute to the consolidation and long-term persistence of an active lifestyle.

To our knowledge, although the efficacy of AIT in relation to cardiometabolic risk factors has been established in several studies, there are no data on the effectiveness of AIT when implemented in conjunction with lifestyle counselling as an intervention in the primary care setting.

The primary aim of this study is to evaluate the effectiveness of different doses (intensities) of supervised exercise training (AIT and TCT), both concomitant with lifestyle counselling, and to compare this with lifestyle counselling (COU) alone as a primary care intervention tool for the management of metabolic syndrome risk factors in low-active adults with one or more such factors.

Secondary aims of the study are to investigate the effects of these interventions on systemic inflammation and adipose tissue function, cardiorespiratory fitness, physical activity and sedentary behaviour, dietary habits, empowerment related to health, self-efficacy in relation to physical activity and dietary habits, as well as the cost-effectiveness of the intervention with regard to health-related quality of life.

The study will also provide insights into the extent to which any observed changes persist in the medium term.

The general hypothesis is that among adults with risk factors for metabolic syndrome, those who participate in interventions designed to promote a healthy lifestyle through a combination of lifestyle counselling and supervised physical exercise of vigorous intensity will present greater improvements in terms of metabolic risk, physical condition, physical activity/sedentary behaviours and psychological parameters at the end of the intervention and at 24-week follow-up than will participants in interventions that combine lifestyle counselling with physical exercise of low-to-moderate intensity or those based exclusively on lifestyle counselling.

\section{Methods}

\section{Trial design}

This is a three-arm (dose-response exercise) randomized controlled clinical trial implemented in the primary care setting over a period of 16 weeks and with 24-week follow-up (Fig. 1).

The study will include two supervised exercise groups with two different doses of exercise intensity (AIT and $\mathrm{TCT}$ ), and a non-exercise control group (COU). All groups will be given lifestyle counselling.

\section{Participants}

\section{Eligibility criteria of participants}

To be eligible, individuals should meet all the following inclusion criteria and none of the exclusion criteria.

\section{Inclusion criteria}

- 30 to 55 years-old.

- Having one or more risk factors for metabolic syndrome $^{1}$ (waist circumference $>94.5 \mathrm{~cm}$ for men and $>89.5 \mathrm{~cm}$ for women; blood pressure $\geq 130$ / $85 \mathrm{mmHg}$; triglycerides in plasma $\geq 150 \mathrm{mg} / \mathrm{dL}$; HDLc in plasma $<40 \mathrm{mg} / \mathrm{dL}$ for men and $<50 \mathrm{mg} / \mathrm{dL}$ for women; fasting glycaemia $\geq 100 \mathrm{mg} / \mathrm{dL}$ ).

- Low active (achieving less than $150 \mathrm{~min} /$ week of moderate-to-vigorous physical activity or to have not participated in any supervised exercise programmes for at least the last 24 weeks).

- Accept and sign written informed consent.

- Accept the randomized group assignment.

\section{Exclusion criteria}

- Morbid obesity (BMI $\geq 40$ ). 


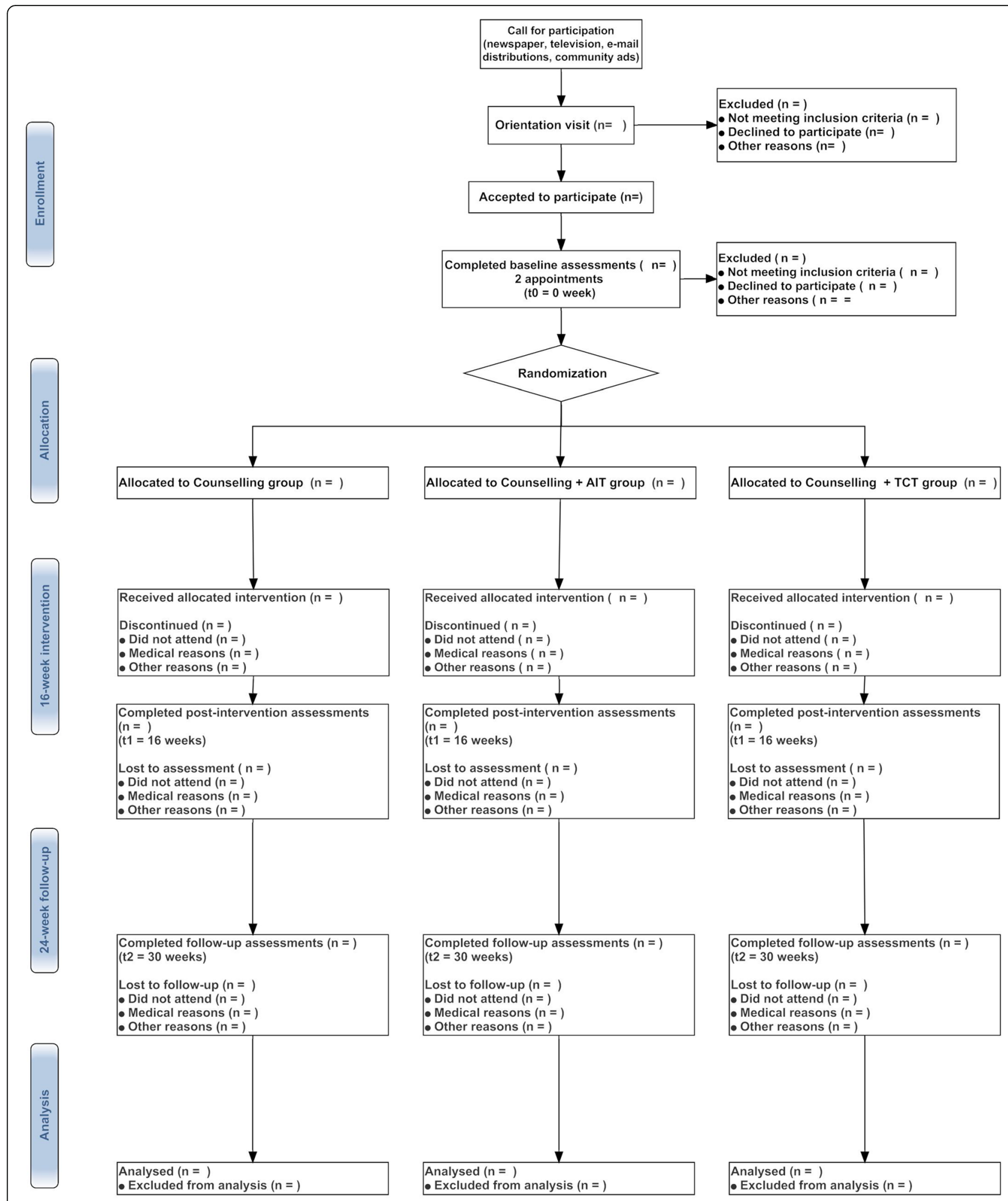

Fig. 1 Bellugat flow chart 
- A past/current history and/or evidence through physical examination or laboratory findings of significant cardiovascular, respiratory, neuromuscular or psychiatric disease/disorder.

- Diseases/disorders that may contraindicate performing physical exercise or a stress test [7].

\section{Enrolment, screening and allocation}

Participants will be recruited through primary healthcare centres, including physician referrals and advertisements through the media, community centres and electronic mailing. Interested individuals will be invited to an information session, where an in-depth detailed explanation of the study requirements and expectations will be given. Any questions will be answered and doubts clarified. Potential eligibility will be checked/confirmed by interview, obtaining information about age, past and current physical activity, medical history and medication use. Eligible participants who wish to participate in the study will be asked to sign written informed consent.

After providing written informed consent individuals will be given an identification number. Participants will be allocated to one of the two supervised physical exercise groups (AIT or TCT) or to the control group (COU), using a computer generated randomized list which allocates at random the identification number of the participant to a treatment group. The allocation sequence will be generated by the IDIAP and will be conducted without influence of the principal investigators.

\section{Blinding}

Due to the nature of the intervention, blinding of participants will not be possible as each of them will be aware of the kind of physical exercise they are engaged in. However, during data analysis researchers will be blinded to the intervention allocated to each participant.

\section{Sample size}

At least 105 individuals will be recruited for this study. Based on previous studies [20], a sample of this size would provide a beta risk of 0.2 and an alpha risk of 0.05 when using a bilateral contrast to detect a mean change in waist circumference of $6.0 \mathrm{~cm}$ (SD 5.3). Assuming a $20 \%$ drop-out rate at follow-up, we aim to recruit 35 individuals for each intervention group.

\section{Ethical implications}

The study will be carried out in accordance with the principles of the Declaration of Helsinki, and subsequent revisions, as well as with the Guidelines for Good Practice in Primary Care Research of the Jordi Gol Primary Care Research Institute (IDIAP).
The research protocol has been reviewed and approved (P15/122) by the Institutional Board (CEIC) of the IDIAP, and written informed consent will be obtained from all participants prior to their inclusion in the study. Specifically, all individuals will give their written informed consent in accordance with the principles of the Declaration of Helsinki and the dispositions established in Spanish law (Chapter II, article 7, Royal Decree 223/2004 of 6 February 2004); the consent form will specify that participation in the study is voluntary and that participants may withdraw at any time. This information will be provided both orally and in writing.

In this study, only researchers and health care professionals will have access to participants' data.

The study methods are consistent with the CONSORT guidelines for the reporting of randomized trials [24].

\section{Trial intervention}

The total duration of the trial will be 40 weeks, comprising a 16-week intervention phase and follow-up 24 weeks later. During the intervention phase all groups (AIT, TCT and COU) will be offered lifestyle counselling, alongside which the two exercise groups (AIT and TCT) will take part in a supervised physical exercise programme.

\section{Counselling programme}

The counselling programme consists of six, 50-min group sessions and three individual sessions lasting 40$50 \mathrm{~min}$ each. All these sessions will be conducted at the primary healthcare centre by a nurse trained in physical activity, nutrition and psychological strategies for behaviour change. An interactive participants' guide has been published with the aim of reinforcing the counselling programme [25]. As a general rule, participants will be required, before the sessions, to read certain information (reports or chapters from the guide) or to reflect on the process of behaviour change. These aspects will then be discussed during the group or the individual meetings. Table 1 shows a detailed outline of the aims and activities of these meetings.

Group counselling sessions Group sessions involving no more than 10 participants will be scheduled with the aim of providing counselling on a healthy lifestyle, including physical activity, sedentary behaviour and dietary habits. Strategies for behaviour change will also be introduced as a way of empowering participants. Additionally, these sessions will give participants the opportunity to receive peer support.

Individual sessions The aim of the individual sessions will be to focus in greater depth on each participant's needs. The professional will help the participant to 
Table 1 Aims and activities of healthy lifestyle counselling sessions for all interventions

\begin{tabular}{|c|c|c|c|}
\hline \multirow{4}{*}{$\begin{array}{l}\mathrm{N} \\
1^{\text {st }} \text { Group Session } \\
(\text { week 1) }\end{array}$} & \multirow{4}{*}{$\begin{array}{l}\text { Aims of the session } \\
\text { To explain the programme } \\
\text { To connect with the rest of } \\
\text { the group and establish the } \\
\text { dynamics of the meetings } \\
\text { To become aware of the } \\
\text { benefits of a healthy lifestyle } \\
\text { To establish personal goals } \\
\text { limiting the time spent in } \\
\text { sedentary behaviours }\end{array}$} & \multicolumn{2}{|c|}{ Example of meeting activities/actions (Participant actions unless otherwise specified) } \\
\hline & & $\begin{array}{l}\text { Before the } \\
\text { session }\end{array}$ & $\begin{array}{l}\text { 1. Browse the BELLUGAT guide promoting a healthy lifestyle. } \\
\text { 2. Review the schedule and the programme plan. }\end{array}$ \\
\hline & & $\begin{array}{l}\text { During the } \\
\text { session }\end{array}$ & $\begin{array}{l}\text { Leader's action: } \\
\text { 1. Present the programme: structure, dates, goals, strategies, etc. } \\
\text { 2. Introduce ice-breaker and rapport-building activities. } \\
\text { Participant's action: } \\
\text { 1. Discuss beneficial effects of a healthy lifestyle. } \\
\text { 2. Propose actions to reduce time spent in sedentary behaviours. }\end{array}$ \\
\hline & & $\begin{array}{l}\text { After the } \\
\text { session }\end{array}$ & $\begin{array}{l}\text { 1. Read the guide's article about encouraging a healthier lifestyle. } \\
\text { 2. Establish personal goals to reduce time spent in sedentary behaviors, } \\
\text { based on ideas listed during group session. }\end{array}$ \\
\hline \multirow[t]{3}{*}{$\begin{array}{l}1^{\text {st }} \text { Individual } \\
\text { Session } \\
\text { (week 2) }\end{array}$} & \multirow{3}{*}{$\begin{array}{l}\text { To become aware of the effect } \\
\text { of his/her cardiovascular risk } \\
\text { factors on his/her health status } \\
\text { To establish personal goals for } \\
\text { controlling his/her risk factors } \\
\text { and plan for the actions } \\
\text { needed to succeed in } \\
\text { achieving those goals }\end{array}$} & $\begin{array}{l}\text { Before the } \\
\text { session }\end{array}$ & $\begin{array}{l}\text { Leader's action: } \\
\text { 1. Email results of baseline tests within } 48 \mathrm{~h} \text { of } 1^{\text {st }} \text { session. } \\
\text { Participant's action: } \\
\text { 1. Read reports of basal tests. } \\
\text { 2. Read the guide's article about metabolic risk factors. }\end{array}$ \\
\hline & & $\begin{array}{l}\text { During the } \\
\text { session }\end{array}$ & $\begin{array}{l}\text { 1. Discuss reports with the leader. } \\
\text { 2. Discuss personal risk factors and establish personal goals for the short } \\
\text { ( } 2 \text { weeks), mid ( } 16 \text { weeks), and long term ( } 40 \text { weeks). } \\
\text { 3. Select actions to achieve personal goals to reduce metabolic risk factors. }\end{array}$ \\
\hline & & $\begin{array}{l}\text { After the } \\
\text { session }\end{array}$ & $\begin{array}{l}\text { 1. Place actions needed to achieve risk factor goals in a visible place and } \\
\text { start putting them into practice. }\end{array}$ \\
\hline \multirow[t]{3}{*}{$\begin{array}{l}2^{\text {nd }} \text { Group Session } \\
\text { (week 4) }\end{array}$} & \multirow{3}{*}{$\begin{array}{l}\text { To become aware of the } \\
\text { importance of a good workout } \\
\text { To establish personal goals to } \\
\text { increase physical activity }\end{array}$} & $\begin{array}{l}\text { Before the } \\
\text { meeting }\end{array}$ & $\begin{array}{l}\text { 1. Read guide's article about increasing physical activity. } \\
\text { 2. Reassess personal level of physical activity according to the reported } \\
\text { accelerometer data (guide). }\end{array}$ \\
\hline & & $\begin{array}{l}\text { During the } \\
\text { session }\end{array}$ & $\begin{array}{l}\text { Leader's action: } \\
\text { 1. Provide information about ways to achieve a physically active lifestyle. } \\
\text { 2. Present specific information about training, hydration, and stretching. } \\
\text { 3. Introduce digital resources to help participants be more active. } \\
\text { Participant's action: } \\
\text { 1. Discuss beneficial effects of physical exercise in addition to routine } \\
\text { physical activity. } \\
\text { 2. Brainstorm examples of physical activities and exercise programmes }\end{array}$ \\
\hline & & $\begin{array}{l}\text { After the } \\
\text { session }\end{array}$ & $\begin{array}{l}\text { 1. Establish physical activity plan to be more active at work and in spare } \\
\text { time in the next week. } \\
\text { 2. Record physical activity in the smartphone application (app) or on paper. }\end{array}$ \\
\hline \multirow[t]{3}{*}{$\begin{array}{l}3^{\text {rd }} \text { Group Session } \\
\text { (week 7) }\end{array}$} & \multirow{3}{*}{$\begin{array}{l}\text { To become aware of the } \\
\text { possibilities of exercising at } \\
\text { home, at work and in spare } \\
\text { time using everyday items } \\
\text { To establish personal goals to } \\
\text { increase physical exercise }\end{array}$} & $\begin{array}{l}\text { Before the } \\
\text { meeting }\end{array}$ & $\begin{array}{l}\text { 1. Read and watch the video from the guide about tips to be more } \\
\text { active at home. }\end{array}$ \\
\hline & & $\begin{array}{l}\text { During the } \\
\text { session }\end{array}$ & $\begin{array}{l}\text { Leader's action: } \\
\text { 1. Demonstrate aerobic and strength exercises using stretch bands, } \\
\text { dumbbells and improvised exercise material. } \\
\text { Participant's action: } \\
\text { 1. Work on aerobic and strength exercises with improvised materials. } \\
\text { 2. Share ideas and discuss ways of incorporating physical exercise } \\
\text { into daily routines. }\end{array}$ \\
\hline & & $\begin{array}{l}\text { After the } \\
\text { session }\end{array}$ & $\begin{array}{l}\text { 1. Review the video of the aerobic and strength exercises practiced in } \\
\text { class. } \\
\text { 2. Establish physical exercise goals and record them in the app or on } \\
\text { paper. }\end{array}$ \\
\hline \multirow[t]{3}{*}{$\begin{array}{l}4^{\text {rd }} \text { Group Session } \\
\text { (week 10) }\end{array}$} & \multirow{3}{*}{$\begin{array}{l}\text { To become aware of the } \\
\text { importance of good nutrition } \\
\text { To establish personal goals to } \\
\text { achieve good nutrition }\end{array}$} & $\begin{array}{l}\text { Before the } \\
\text { meeting }\end{array}$ & 1. Read the guide's article about healthy food choices. \\
\hline & & $\begin{array}{l}\text { During the } \\
\text { session }\end{array}$ & $\begin{array}{l}\text { Leader's action: } \\
\text { 1. Provide nformation about healthy benefits of healthy eating. } \\
\text { 2. Present the healthy food pyramid and the Mediterranean diet concept. } \\
\text { Participant's action: } \\
\text { 1. Discuss the beneficial effects of healthy nutrition. } \\
\text { 2. Brainstorm different ways of making healthy food choices. }\end{array}$ \\
\hline & & $\begin{array}{l}\text { After the } \\
\text { session }\end{array}$ & $\begin{array}{l}\text { 1. Identify unhealthy food choices made and record them in the app } \\
\text { or on paper. }\end{array}$ \\
\hline
\end{tabular}


Table 1 Aims and activities of healthy lifestyle counselling sessions for all interventions (Continued)

\begin{tabular}{|c|c|c|c|}
\hline \multirow[t]{3}{*}{$\begin{array}{l}2^{\text {nd }} \text { Individual } \\
\text { Session } \\
\text { (week 12) }\end{array}$} & \multirow{3}{*}{$\begin{array}{l}\text { To assess the current routine } \\
\text { of physical activity and } \\
\text { exercise and establish new } \\
\text { strategies if necessary } \\
\text { To become aware of the effect } \\
\text { of good nutrition on his/her } \\
\text { health status } \\
\text { To establish personal } \\
\text { nutritional goals and the } \\
\text { actions needed to achieve } \\
\text { them }\end{array}$} & $\begin{array}{l}\text { Before the } \\
\text { meeting }\end{array}$ & $\begin{array}{l}\text { Leader's action: } \\
\text { 1. Email results of baseline dietary habits questionnaire within } 48 \mathrm{~h} \\
\text { of } 2^{\text {nd }} \text { session. } \\
\text { Participant's action: } \\
\text { 1. Carry out a self-assessment of the establishment of physical } \\
\text { activity/exercise goals and the progress made. } \\
\text { 2. Read report of baseline dietary habits questionnaire. } \\
\text { 3. Read the guide's article about strategies to overcome nutritional barriers. }\end{array}$ \\
\hline & & $\begin{array}{l}\text { During the } \\
\text { session }\end{array}$ & $\begin{array}{l}\text { 1. Review progress and resolve problems or setbacks in active lifestyle } \\
\text { goal-setting and action planning. } \\
\text { 2. Highlight positive changes and define potential ways forward, } \\
\text { building on successes. } \\
\text { 3. Discuss the dietary habits report with the leader and agree on } \\
\text { personal goals. } \\
\text { 4. Identify possible barriers to healthy eating and select } \\
\text { actions/strategies to overcome them. }\end{array}$ \\
\hline & & $\begin{array}{l}\text { After the } \\
\text { session }\end{array}$ & $\begin{array}{l}\text { 1. Develop physical activity and exercise plan for the upcoming weeks. } \\
\text { 2. Place actions needed to achieve active lifestyle goals in a visible } \\
\text { place and start putting them into practice. }\end{array}$ \\
\hline \multirow[t]{3}{*}{$\begin{array}{l}6^{\text {rd }} \text { Group Session } \\
\text { (week 16) }\end{array}$} & \multirow{3}{*}{$\begin{array}{l}\text { To become aware of barriers } \\
\text { to new activity and nutritional } \\
\text { behaviors and devise } \\
\text { strategies to overcome them } \\
\text { To establish new strategies to } \\
\text { overcome barriers and } \\
\text { maintain a new healthy } \\
\text { lifestyle }\end{array}$} & $\begin{array}{l}\text { Before the } \\
\text { meeting }\end{array}$ & $\begin{array}{l}\text { 1. Read guide's article about other healthy habits such as sleep and rest, } \\
\text { reduce stress, no smoking, etc. } \\
\text { 2. Review goals and think about new actions to overcome barriers. }\end{array}$ \\
\hline & & $\begin{array}{l}\text { During the } \\
\text { session }\end{array}$ & $\begin{array}{l}\text { Leader's action: } \\
\text { 1. Provide information about maintaining a healthy lifestyle. } \\
\text { 2. Resolve doubts and facilitate access to additional resources that } \\
\text { may be needed. } \\
\text { Participant's action: } \\
\text { 1. Share strategies to overcome barriers to new active lifestyle and } \\
\text { dietary habits. } \\
\text { 2. Brainstorm ideas to use the physical and social environment to } \\
\text { become healthier. }\end{array}$ \\
\hline & & $\begin{array}{l}\text { After the } \\
\text { session }\end{array}$ & $\begin{array}{l}\text { 1. Review materials, acquired knowledge and strategies. } \\
\text { 2. Think about how to apply them in oneself current situation. }\end{array}$ \\
\hline \multirow[t]{3}{*}{$\begin{array}{l}3^{\text {rd }} \text { Individual } \\
\text { Session } \\
\text { (weeks 18-19) }\end{array}$} & \multirow[t]{3}{*}{$\begin{array}{l}\text { To become aware of the } \\
\text { effects of oneself new lifestyle } \\
\text { on reducing } \\
\text { cardiovascular risk factors } \\
\text { To establish new weekly } \\
\text { personal goals for the next } \\
6 \text { months }\end{array}$} & $\begin{array}{l}\text { Before the } \\
\text { meeting }\end{array}$ & $\begin{array}{l}\text { Leader's action: } \\
\text { 1. Email results of post-intervention tests within } 48 \mathrm{~h} \text { of } 1^{\text {st }} \text { session. } \\
\text { Participant's action: } \\
\text { 1. Read the email reports of post-intervention results. } \\
\text { 2. Review initial metabolic risk factors results emailed after } 1^{\text {st }} \text { group } \\
\text { session. }\end{array}$ \\
\hline & & $\begin{array}{l}\text { During the } \\
\text { session }\end{array}$ & $\begin{array}{l}\text { 1. Analyse progress based on } 16 \text {-week follow-up report after } 16 \text { weeks) } \\
\text { and resolve problems or setbacks. } \\
\text { 2. Highlight positive changes and discuss potential ways forward. } \\
\text { 3. Agree on relapse prevention plans (active lifestyle and healthy eating) } \\
\text { for the next } 6 \text { months. }\end{array}$ \\
\hline & & $\begin{array}{l}\text { After the } \\
\text { session }\end{array}$ & $\begin{array}{l}\text { 1. Maintain a new healthy lifestyle. } \\
\text { 2. Keep a log of physical activity/exercise and eating habits, supported } \\
\text { by the BELLUGAT app. } \\
\text { 3. Consult the programme guide, other educational material provided, } \\
\text { and physical activity or primary healthcare professionals, as needed. }\end{array}$ \\
\hline
\end{tabular}

establish realistic daily goals for physical activity and will involve him/her in the decision-making process. The session will be based on the transtheoretical model of behaviour-change [26] and on motivational interviewing [27].

\section{Supervised physical exercise}

The supervised exercise programme will be offered to both exercise groups (AIT and TCT) and will consist of 16 supervised group training sessions lasting $50 \mathrm{~min}$ each and 32 non-supervised individual training sessions (i.e. self-administered by each participant).

The supervised training sessions will be run by experts in physical exercise (sports centre based), who will also deliver the instructions for the self-administered sessions.

Structure of the training sessions All training lessons will comprise five parts: introduction (aims and contents), warm-up, main part (differing between the AIT and TCT groups, see below), cool-down, and stretching 
and conclusions (instructions for self-administered sessions).

The main part will differ between groups and consists of:

- AIT group: Four series of 4 min of cycling at a heart rate of $80 \%$ of the $\mathrm{VO}_{2 \text { peak }}$ registered previously during the stress test, with active pauses of $2 \mathrm{~min}$ at $60 \%$ of the $\mathrm{VO}_{\text {2peak }}$ between them (Table 2).

Given that maintaining the anticipated exercise intensity might, at the beginning of the programme, excessively burden participants allocated to this group, the length of the series will be shorter during the initial sessions. Thus, intensity will be established at $80 \%$ of the $\mathrm{VO}_{2 \text { peak }}$ but series will last for 1 min during the first week, after which they will be increased by $1 \mathrm{~min}$ each successive week until reaching a duration of four minutes. At the same time, active pauses will be shortened so as to accumulate an exercise time of $24 \mathrm{~min}$ in that part of the session.

- TCT group: Participants allocated to this group will perform activities such as walking, cycling, team activities and toning exercises, always at an intensity of $60 \%$ of their $\mathrm{VO}_{2 \text { peak }}$. The number of training sessions per week and the ratio of supervised to self-administered sessions will be the same as that shown in Table 2 for the AIT group.

Programme monitoring Both training groups will perform the first eight sessions using indoor cycling ergometers, another four lessons using a treadmill and the remainder in outdoor green areas of the city.

Across the sixteen sessions participants will be able to practise and to become familiar with a variety of exercise forms, while keeping to the training goals. The aim is that this experience allows them to feel more empowered with respect to physical activity.

At the beginning of the programme, participants will be given a heart rate monitor (Geonaute, ONRhythm 110, Oxylane, Villeneuve d'Ascq, France) that will be used to monitor the training intensity during supervised and self-administered sessions.

Additionally, a web-based application will be used to monitor and provide feedback for the self-administered training sessions.

\section{Educational resources}

Educational resources for supporting the counselling programme, such as the participants' guide [25], have been validated by means of Delphi qualitative techniques [28], patient interview, quantitative questionnaires [29, 30] and the INFELZ software [31].

\section{Outcome measures}

Measurements will be taken before ( $\mathrm{t} 0=0$ months) and after ( $\mathrm{t} 1=16$ weeks) the intervention. As a mediumterm follow-up measure, the exercise and control groups

Table 2 Weekly schedule for the main part of the AIT program sessions

\begin{tabular}{|c|c|c|c|c|c|}
\hline \multirow{2}{*}{$\begin{array}{l}\text { Week } \\
\text { number }\end{array}$} & \multirow{2}{*}{$\begin{array}{l}\text { Supervised/self- } \\
\text { administered } \\
\text { lessons }(n / n)\end{array}$} & \multicolumn{4}{|c|}{ Content of the main part of the AIT sessions } \\
\hline & & $\begin{array}{l}\text { Work volume } \\
\text { (Rep } \times \text { time) }\end{array}$ & $\begin{array}{c}\text { Work Intensity } \\
\left(\% \mathrm{VO}_{2 \text { peak }}\right)\end{array}$ & $\begin{array}{l}\text { Active rest } \\
\text { (time) }\end{array}$ & $\begin{array}{c}\text { Total accumulated } \\
\text { time }\end{array}$ \\
\hline 1 & $2 / 1$ & $16 \times 1^{\prime}$ & 80 & $30^{\prime \prime}$ & $24^{\prime}$ \\
\hline 2 & $2 / 1$ & $8 \times 2^{\prime}$ & 80 & $1^{\prime}$ & $24^{\prime}$ \\
\hline 3 & $2 / 1$ & $5 \times 3^{\prime}$ & 80 & $2^{\prime}$ & $25^{\prime}$ \\
\hline 4 & $2 / 1$ & $4 \times 4^{\prime}$ & 80 & $2^{\prime}$ & $24^{\prime}$ \\
\hline 5 & $1 / 2$ & $4 \times 4^{\prime}$ & 80 & $2^{\prime}$ & $24^{\prime}$ \\
\hline 6 & $1 / 2$ & $4 \times 4^{\prime}$ & 80 & $2^{\prime}$ & $24^{\prime}$ \\
\hline 7 & $0 / 3$ & $4 \times 4^{\prime}$ & 80 & $2^{\prime}$ & $24^{\prime}$ \\
\hline 8 & $1 / 2$ & $4 \times 4^{\prime}$ & 80 & $2^{\prime}$ & $24^{\prime}$ \\
\hline 9 & $1 / 2$ & $4 \times 4^{\prime}$ & 80 & $2^{\prime}$ & $24^{\prime}$ \\
\hline 10 & $0 / 3$ & $4 \times 4^{\prime}$ & 80 & $2^{\prime}$ & $24^{\prime}$ \\
\hline 11 & $1 / 2$ & $4 \times 4^{\prime}$ & 80 & $2^{\prime}$ & $24^{\prime}$ \\
\hline 12 & $1 / 2$ & $4 \times 4^{\prime}$ & 80 & $2^{\prime}$ & $24^{\prime}$ \\
\hline 13 & $0 / 3$ & $4 \times 4^{\prime}$ & 80 & $2^{\prime}$ & $24^{\prime}$ \\
\hline 14 & $1 / 2$ & $4 \times 4^{\prime}$ & 80 & $2^{\prime}$ & $24^{\prime}$ \\
\hline 15 & $0 / 3$ & $4 \times 4^{\prime}$ & 80 & $2^{\prime}$ & $24^{\prime}$ \\
\hline 16 & $1 / 2$ & $4 \times 4^{\prime}$ & 80 & $2^{\prime}$ & $24^{\prime}$ \\
\hline
\end{tabular}

AIT aerobic interval training; $n$, number, Rep repetitions, $V O_{2 p e a k}$, peak oxygen uptake 
will also be assessed 24 weeks later (t2) (Fig. 1). Table 3 shows a detailed outline of the outcome measurements.

All assessments will be divided into two appointments. In the first appointment, fasting blood samples will be drawn through an antecubital vein, and anthropometric (body mass, height, waist and hip circumferences) and body composition measures (percentage of fat) will be obtained. Also during this appointment, accelerometers will be positioned on the participants' waist and they will be given instructions on how to complete an activity log during the 7-day period that they will wear the accelerometers.

Table 3 BELLUGAT protocol schedule form and procedures for all interventions

\begin{tabular}{|c|c|c|c|c|c|}
\hline Time point & $\begin{array}{c}\text { Enrolment } \\
\mathrm{t}-1\end{array}$ & $\begin{array}{c}\text { Baseline assessment } \\
\text { t0 }\end{array}$ & Allocation & $\begin{array}{c}\text { +16 weeks assessment } \\
\text { t1 }\end{array}$ & $\begin{array}{c}+24 \text { weeks assessment } \\
\text { t2 }\end{array}$ \\
\hline \multicolumn{6}{|l|}{ Preliminary data: } \\
\hline Eligibility screen & $\checkmark$ & & & & \\
\hline Informed consent & $\checkmark$ & & & & \\
\hline Allocation & & & $\checkmark$ & & \\
\hline \multicolumn{6}{|l|}{ Anthropometric measurements } \\
\hline Body mass & & $\checkmark$ & & $\checkmark$ & $\checkmark$ \\
\hline Height & & $\checkmark$ & & $\checkmark$ & $\checkmark$ \\
\hline Body mass index & & $\checkmark$ & & $\checkmark$ & $\checkmark$ \\
\hline Waist circumference & & $\checkmark$ & & $\checkmark$ & $\checkmark$ \\
\hline Hip circumference & & $\checkmark$ & & $\checkmark$ & $\checkmark$ \\
\hline \multicolumn{6}{|l|}{ Blood sampling and biochemical measurements } \\
\hline Lipid profile (TG, TC, HDLC, LDLC) & & $\checkmark$ & & $\checkmark$ & $\checkmark$ \\
\hline Plasma glucose & & $\checkmark$ & & $\checkmark$ & $\checkmark$ \\
\hline Plasma glycated haemoglobin & & $\checkmark$ & & $\checkmark$ & $\checkmark$ \\
\hline Plasma adiponectin & & $\checkmark$ & & $\checkmark$ & $\checkmark$ \\
\hline Plasma Interleucin-6 & & $\checkmark$ & & $\checkmark$ & $\checkmark$ \\
\hline Plasma metabolome-lipidome & & $\checkmark$ & & $\checkmark$ & $\checkmark$ \\
\hline Plasma MicroRNA & & $\checkmark$ & & $\checkmark$ & $\checkmark$ \\
\hline \multicolumn{6}{|l|}{ Medical procedures } \\
\hline Resting blood pressure & & $\checkmark$ & & $\checkmark$ & $\checkmark$ \\
\hline Cardiorespiratory fitness $\left(\mathrm{VO}_{2}\right.$ peak) & & $\checkmark$ & & $\checkmark$ & $\checkmark$ \\
\hline \multicolumn{6}{|l|}{ Physical activity and sedentary behaviour } \\
\hline Physical activity (LPA and MVPA) & & $\checkmark$ & & $\checkmark$ & $\checkmark$ \\
\hline Sedentary time & & $\checkmark$ & & $\checkmark$ & $\checkmark$ \\
\hline \multicolumn{6}{|l|}{ Self-reported Questionnaires } \\
\hline Food frequency questionnaire & & $\checkmark$ & & $\checkmark$ & $\checkmark$ \\
\hline Healthy eating index & & $\checkmark$ & & $\checkmark$ & $\checkmark$ \\
\hline Empowerment related to health & & $\checkmark$ & & $\checkmark$ & $\checkmark$ \\
\hline Physical activity and dietary habits self-efficacy & & $\checkmark$ & & $\checkmark$ & $\checkmark$ \\
\hline Health related quality of life (EQ-5D) & & $\checkmark$ & & $\checkmark$ & $\checkmark$ \\
\hline Direct costs & & & & $\checkmark$ & \\
\hline Indirect costs & & & & $\checkmark$ & \\
\hline Demographic variables & & $\checkmark$ & & & \\
\hline Enjoyment with the programme & & & & $\checkmark$ & \\
\hline Reasons for abandoning & & $\checkmark$ & & $\checkmark$ & $\checkmark$ \\
\hline
\end{tabular}


In the second assessment appointment, participants will be asked to complete the questionnaires on healthrelated quality of life, self-efficacy, empowerment and dietary habits. Resting (recumbent and sitting) ECG and blood pressure measures will then be taken. Finally, participants will also complete a voluntary maximal graded test on a cycle ergometer.

Accelerometers will be retrieved at the end of the 7day period during which participants have recorded their free-living movement.

\section{Risk factors for metabolic syndrome}

Anthropometry and visceral adiposity Body mass (precision: $0.1 \mathrm{~kg}$ ) and height (precisions $(0.1 \mathrm{~cm})$ will be measured with a scale (SECA 711, Hamburg, Germany) and stadiometer (Año-Sayol, Barcelona, Spain), with the participant in underwear and barefoot, following standard procedures [32]. Body mass index (BMI) will be calculated by dividing body mass $(\mathrm{kg})$ by height $\left(\mathrm{m}^{2}\right)$.

Waist circumference (WC) (precision: $0.1 \mathrm{~cm}$ ) will be measured in triplicate at the end of several consecutive natural breaths, at a level parallel to the floor, at the midpoint between the top of the iliac crest and the lower margin of the last palpable rib in the mid-axillary line. Hip circumference $(\mathrm{HC})(0.1 \mathrm{~cm})$ will also be measured in triplicate at a level parallel to the floor, at the largest circumference of the buttocks. Both measures will be made with a stretch-resistant tape and without constricting [33]. The mean of the three measurements will be used in the waist-to-hip ratio calculation (WtHr).

Blood pressure Blood pressure (BP) will be measured at the level of the brachial artery of the dominant arm using an automated device (Omron M, Omron Healthcare Europe B.V. Hoofddorp, The Netherlands), with participants in a relaxed sitting position. Measurements will be taken in duplicate, 2 min apart. The latter of these will be recorded [34].

Plasma biochemistry Blood samples for the determination of plasma triglycerides (TG), total cholesterol (TC), low-density lipoprotein cholesterol (LDLc), highdensity lipoprotein cholesterol (HDLc), glycated haemoglobin (HbA1c) and glucose will be drawn after an overnight fast, with participants in a sitting position. Blood samples will be analysed with automated methods at the laboratory of the Arnau de Vilanova University Hospital (Lleida).

\section{Metabolic risk score}

A continuous metabolic syndrome risk score (cMSSy) will be calculated, as described by Wijndaele [35]. The score contains the five risk factors considered in the definition of metabolic syndrome [1, 36], namely waist circumference, TG, HDLc, systolic blood pressure (SBP) and plasma glucose.

\section{Systemic inflammation and adipose tissue parameters}

Fasting blood samples will also be used to determine inflammation parameters (adiponectin and interleukin (IL)6). Inflammation parameters will be measured by immune assay using high sensitivity MILLIPLEX XMap commercial kits (Millipore, Billerica, MA, USA). The visceral adipose tissue index will be calculated following the procedure described by Amato [37]; which relates waist circumference, body mass index, triglycerides and HDLc.

\section{Plasma microRNA determination}

We will analyse miR-197, miR-23a, miR-509-5p, miR130a-b, miR-195, miR-27a and miR-320, which are known to be deregulated and associated with features of metabolic syndrome. Targeted microRNA will be determined after its extraction from blood samples, following the instructions provided with the MagMax mirVana RNA isolation kit. In addition, any microRNA will be quantified by a specific TaqMan Advanced miRNA assay.

\section{Untargeted and targeted metabolomics and lipidomics}

Metabolomics and lipidomics will be performed after the extraction of metabolites and lipids from plasma/serum at the baseline and final stages of the experiments. Metabolites and lipids will be separated by UPLC and detected by QTOF and TQP, depending on the procedure. Species identification will be performed via the PCDL database of Agilent Technologies, which uses retention times in a standardized chromatographic system as an orthogonal searchable parameter to complement accurate mass data (accurate mass retention time approach). In both cases, the SMPDB database [38, 39] will be used for querying metabolites obtained from the HMDB search, using a $0.05 \mathrm{Da}$ M.W. tolerance and the Metaboanalyst platform $[40,41]$ for the determination of differential features.

\section{Cardiorespiratory fitness}

Cardiorespiratory fitness will be assessed by means of voluntary maximal graded exercise on a cycle ergometer (Monark 828E, Monark, Sweden).

Before the exercise test, measures will be taken of heart rate and systolic (SBP) and diastolic (DBP) blood pressure, along with a resting electrocardiogram (ECG). Electrocardiographic leads will be positioned according to Mason-Likar placement [42].

These tests will be performed at a constant cadence of $60 \mathrm{rpm}$. The warm-up stage will be $2 \mathrm{~min}$ at $10 \mathrm{~W}$ (W). The stepwise graded exercise will then begin, with increases of $20 \mathrm{~W}$ every two minutes until volitional fatigue or until participants cannot maintain the pre- 
established cadence. The recovery stage will be $3 \mathrm{~min}$ at the load selected by the participant.

During the graded exercise, oxygen uptake and ventilation will be measured using the Oxycon Mobile metabolic system (Oxycon Mobile, Carefusion, Germany). Gas calibrations will be conducted before each test. Heart rate will be measured using a Polar 610 s chest heart rate monitor (Polar Electro YO, Kempele, Finland) and an electrocardiographic device (Kaunas Load System, Kaunas, Lithuania).

SBP and DBP will be measured using a manual device (Omrom M, Omron Healthcare Europe B.V. Hoofddorp, The Netherlands) at rest, every 2 min during the final $30 \mathrm{~s}$ of each stage and at 2, 4 and 6 min of the recovery.

Ratings of perceived exertion (RPE) will be obtained every 2 min using the 10-point Borg scale [43].

Capillary blood samples $(200 \mu \mathrm{L})$ from the ear lobe will be taken at baseline and at the sixth minute of the post-exercise period for the analysis of plasma changes due to exertion (miRNA determination and untargeted and targeted metabolomics and lipidomics).

Data from the exercise test will be recorded for the screening of abnormal BP and ECG responses, eliciting either $\mathrm{VO}_{2 \max }$ or $\mathrm{VO}_{2 \text { peak }}$, as well as for determining subsequent exercise prescriptions. The criteria for achieving $\mathrm{VO}_{2 \max }$ will be RER $>1.1$, a plateau in $\mathrm{VO}_{2}$ (change of $<100 \mathrm{~mL} \cdot \mathrm{min}^{-1}$ in the final two consecutive stages), and a HR within 10 beats $\cdot \min ^{-1}$ of the maximal level predicted by age [7]. Those participants who do not meet these criteria will be classified as having reached their $\mathrm{VO}_{2 \text { peak }}$.

The cycle ergometer test is preferred here to the treadmill test because it is easier to take the ECG and BP measurements, and because during the intervention most of the training sessions will be group indoor cycling, and hence the transfer of prescribed heart rate will be more valid. In addition, cycle ergometry is safer than treadmill testing.

\section{Physical activity habits and sedentary behaviour}

Active and sedentary habits will be assessed objectively by accelerometry using the ActiGraph GT3X+ accelerometer (ActiGraph LLC, Pensacola, FL, USA) over eight consecutive days. Accelerometers will be positioned laterally on each participant's waist and attached with an elastic belt. Participants will be instructed to wear the accelerometer all day, including during sleep. Accelerometers will be programmed to register the movement in 60-s epochs and data will be downloaded and analysed with ActiLife 6.0 software (ActiGraph, Pensacola, FL, USA). Sleeping hours and 20-min bouts of consecutive zero counts will be excluded from the analysis. Data from accelerometers will be analysed to yield an overall physical activity index (expressed as vector magnitude in mean counts per minute (CPM)) and the percentage of registered time spent in different levels of sedentary behaviour or physical activity (PA). The cutoff points for the categorization of movement intensity will be defined as follows: sedentary behaviour (SB) (<100 CPM); light physical activity (LPA) (100 to 2019 CPM) and moderate-to-vigorous physical activity (MVPA) (>2020 CPM) [44]. Sedentary behaviour will be assessed as the total time engaged in sedentary behaviour and as the daily number and length of sedentary periods. The assessment of physical activity and sedentary behaviour will be complemented with a log of the activities performed during the days on which participants wear the accelerometers.

\section{Dietary habits}

Data regarding participants' dietary habits will be obtained using the adult version of the food frequency questionnaire (FFC) [45]. This questionnaire consists of a list of food groups, with participants being required to indicate their intake frequency (daily, weekly or monthly) for each component on the list. This questionnaire has been used previously in longitudinal dietary studies and in studies relating dietary patterns and biological parameters in adults [46].

The Healthy Eating Index $[47,48]$ will be calculated to assess and monitor participants' dietary status. The Healthy Eating Index (HEI) comprises 10 items, each representing different features of a healthy diet: items 1 to 5 measure the degree of agreement with national dietary guidelines for grains, vegetables, fruit, milk and meat. Items 6 and 7 measure the percentage of total fat and saturated fat in the total energy intake, items 8 and 9 measure cholesterol and sodium intake, and item 10 examines the variety of the respondent's diet.

\section{Empowerment and self-efficacy}

Empowerment related to health will be measured with the Spanish version of the Health Empowerment Scale (HES) [49]. This instrument contains 8 items (self-control, self-efficacy, problem solving, psychological coping, stress management, support motivation and decisionmaking) that are scored on a 5-point Likert scale rating from 5 (strongly agree) to 1 (strongly disagree). Higher scores indicate greater levels of health-related empowerment. The Spanish version of the HES achieved a Cronbach's alpha (internal consistency) of 0.89 , and its content validity is supported by scale and item content validity indexes of 0.98 and 1.0 , respectively.

Self-efficacy in relation to physical exercise and dietary habits will be measured with a questionnaire created ad hoc in accordance with the guidelines of Bandura [50]. This instrument comprises 17 items related to physical exercise and 10 items related to dietary habits. Each item 
is scored on a 100-point scale ranging, in 10-unit intervals, from 0 (cannot do it at all) to 100 (highly certain I can do it). Higher scores indicate greater levels of selfefficacy in relation to exercise and dietary habits.

\section{Health-related quality of life}

Health-related quality of life (HRQoL) will be determined with the Spanish version of the EuroQoL group EQ-5D questionnaire for adults [51]. The EQ-5D comprises questions related to five dimensions: mobility, self-care, usual activities, pain/discomfort and anxiety/depression. Each dimension has five levels ranging from "no problems" to "extremely important problems". The EQ-5D also includes a vertical visual analogue scale (EQ VAS) on which respondents self-rate their current perception of health between the endpoints: ' $100=$ Best imaginable health state' and ' $0=$ Worst imaginable health state'. The EQ-5D has shown reliability of 0.86 to 0.90 .

\section{Cost analysis}

Direct and indirect costs of setting up and running the interventions will be calculated in order to assess the economic aspect. HRQoL scores will be used to weight survival years and, thus, to generate QALYs (Quality Adjusted Life Years). The cost-effectiveness analysis will be conducted in accordance with the current practice methods for economic assessment [52]. The primary cost-effectiveness outcome will be a reduction in the metabolic risk score.

\section{Other measures}

Demographic and other variables Variables such as demographic characteristics, personal and family medical history, and medication use will also be registered.

\section{Questionnaires used during the intervention phase} During the intervention phase several questionnaires will be used to assess the degree of enjoyment with [53] or the reasons for abandoning the exercise programme.

\section{Data analysis \\ Timeline of data measurements}

Measurements will be taken before (Baseline, $\mathrm{t} 0=0$ months) and after ( $\mathrm{t} 1=16$ weeks) the intervention. As a mediumterm follow-up measure, the two intervention groups and the control group will also be assessed 24 weeks after the end of the programme (t2).

\section{Data management}

Confidentiality will be ensured by coding participants' personal data, to which only the researchers and health care professionals will have access.

After randomization, participants will receive an randomization code (unique for each participant and blinded for the statistician). All data will be analysed according to this randomization code. The key to the source data will only be known by the researchers and the research coordinator. The researchers will be familiar with the study procedure, be trained prior to the study and will collect all data for this study.

\section{Statistical methods}

An initial overview analysis will be carried out to detect any errors and to check the data for normality (ShapiroWilks test), this being done for all participants and intervention groups.

Intention-to-treat (ITT) analysis will be performed for all recruited participants who complete the baseline assessment, regardless of whether they subsequently complete the whole protocol. Missing outcome values will be replaced by data registered in the previous assessment using the last observation carried forward (LOCF) technique.

For the baseline comparison of groups we will use the chi-square test (or Fisher's exact test) for categorical data and the analysis of variance (ANOVA) (or Kruskall-Wallis test) for quantitative data (continuous or ordinal). If significant differences are detected we will use Student's $t$-test (or Mann-Whitney test) for each pair of groups.

For the analysis of the intervention effect two time frameworks will be established: efficacy (at the end of the intervention: t1) and durability (at 24-week followup: t2). Change will be calculated as the change from baseline values, both as absolute values and as a percentage adjusted to baseline values. We will adjust repeated measures techniques to study the general behaviour of the outcomes in the follow-up.

Continuous variables will be expressed as mean and standard deviation (SD). Effect size will be estimated as the mean standardized difference between the mean of each group divided by the pooled standard deviation. In accordance with Cohen's criterion [54], values of $0.2-0.5$ represent small differences, $0.5-0.8$ moderate differences and $>0.8$ large differences. Categorical variables will be expressed as counts (n) and percentages (\%), unless otherwise specified.

All analyses will be conducted using the Statistical Package for the Social Sciences (SPSS) v17 (SPSS Institute Inc., IL, USA) and the level of significance will be set at $p<0.05$.

\section{Risk and burdens}

The main expected difficulties are a low adherence rate and the impossibility of blinding the intervention to participants and researchers. However, we will seek to minimize the former by individualizing attention (providing and discussing written feedback reports) 
during the implementation phase and the latter by blinding researchers to the group to which individuals were allocated.

\section{Discussion}

In its 2008-2013 action plan the WHO [55] states, among others, the following aims: a) the promotion of interventions for the prevention and control of the main modifiable risk factors for non-communicable disease, b) the implementation of actions to help individuals to enhance their self-efficacy, improving literacy and providing tools for self-control, and c) the promotion of research to establish the cost/efficacy relationship of these interventions. We believe that with our study design we focus on these key aspects.

Current evidence indicates that AIT may be a valuable physical exercise strategy in terms of improving cardiac and metabolic risk status, functional capacity and quality of life [12, 18, 20]. AIT has demonstrated consistently better results than TCT when it comes to improving $\mathrm{VO}_{2 \max }$. Given that the $\mathrm{VO}_{2 \max }$ is associated with premature mortality and cardiovascular risk [56] the potential ability of AIT to improve this parameter is, from the health perspective, a promising finding. However, although the efficacy of AIT to induce physiological improvements in a well-controlled research environment is no longer in doubt, questions remain regarding the extent to which its benefits are transferable to a lesscontrolled clinical environment [21]. A further issue is that the evidence regarding the effectiveness of more traditional programmes for promoting physical activity is also inconsistent [57]. This study aims to address this issue by evaluating the effectiveness of AIT versus TCT (both concomitant with lifestyle counselling) as a primary care intervention for the management of metabolic syndrome risk factors in low-active adults presenting one or more of such factors.

A major strength of our study is its design, which will shed light on the extent to which 1) an AIT programme is a viable tool for implementation in the primary care setting, and 2) whether individuals will remain compliant with the programme in the medium term without supervision. Our study is unique as, unlike other AIT studies, it considers not only the physical exercise aspect but also links this to strategies for behaviour change and empowerment of individuals. According to Biddle [58], structured physical exercise programmes led by competent professionals are more effective at encouraging sedentary individuals to become more active than are poorly structured programmes or programmes that are self-administered at home. However, in order to achieve long-lasting and successful outcomes these programmes need to include psychological goals and strategies (mood, literacy, self-efficacy, social integration) focused on behaviour change. In this regard, our study includes a lifestyle counselling intervention that incorporates strategies for promoting regular physical activity, minimizing sedentary behaviour, improving dietary habits and enhancing participants' self-efficacy. To our knowledge, this would be the first study in Spain to analyse the effect of AIT in conjunction with strategies to promote behaviour change and empower participants.

Another important feature of our study is that, alongside the assessment of changes in traditional metabolic risk factors after the intervention, we will also examine its effect on systemic inflammatory status [5, 59], cardiorespiratory fitness, self-efficacy for physical activity and dietary habits, empowerment related to health and health-related quality of life, as well as changes in physical activity levels, sedentary behaviour and dietary habits.

As noted by Marrugat et al. [60], the most efficient way of controlling the economic burden of public health and the mortality rates associated with cardiovascular diseases is to reduce their prevalence. One of the strategies for doing so could be the implementation of interventions designed to promote a healthy lifestyle, but in order to establish public health priorities it is first necessary to determine the cost effectiveness of such interventions. Consequently, the present study, in addition to examining the effects on physiological, psychological and behavioural parameters, will also assess the economic impact of the intervention.

The results of this study will provide insight into the immediate and medium-term effects on metabolic risk and lifestyle of the combination of AIT with a multidisciplinary behavioural intervention. If effective, the proposed intervention would provide both researchers and practitioners in this field with a platform on which to develop similar intervention programmes for tackling the repercussions of an unhealthy lifestyle.

\footnotetext{
Abbreviations

AIT: Aerobic Interval Training; ANOVA: analysis of the variance; BMI: Body Mass Index; BP: Blood Pressure; cMSSy: Metabolic Syndrome Risk Score; COU: counselling; CPM: Counts Per Minute; DBP: Diastolic Blood Pressure; ECG: Electrocardiogram; EQ VAS: EQ Visual Analogue Scale; EQ-5D: EQ-5D questionnaire; FFC: Food Frequency Questionnaire; HbA1c: Glycated haemoglobin; HC: Hip Circumference; HDLc: High Density Lipoprotein cholesterol; HEl: Healthy Eating Index; HES: Health Empowerment Scale; HIIT: High-Intensity Interval Training; HRQoL: Health Related Quality of Life; IDIAP: Primary Care Research Institute-Jordi Gol; IL-6: interleukin-6; ITT: Intention-To-Treat; LDLc: Low Density Lipoprotein cholesterol; LOCF: Last Observation Carried Forward technique; LPA: Light Physical Activity; miRNA: microRNA; MVPA: Moderate-to-Vigorous Physical Activity; PA: Physical Activity; PCDL: Personal Compound-Database and Library; QALYs: Quality Adjusted Life Years; QTOF: Quadrepole Time-Of-Flight; RER: Respiratory Exchange Ratio; RNA: Ribonucleic Acid; RPE: Ratings of Perceived Exertion; Rpm: Revolutions per minute; SBP: Systolic Blood Pressure; SMPDB: Small Molecule Pathway Database; TC: Total Cholesterol; TCT: Traditional Continuous Training; TG: Triglycerides; TQP: Triple-Quadre-Pole; UPLC: Ultra Performance Liquid Chromatography; $\mathrm{VO}_{2}$ : Oxygen uptake; $\mathrm{VO}_{2 \mathrm{max}}$ :

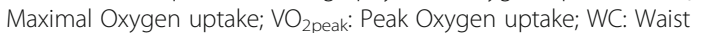
Circumference; WHO: World Health Organisation; WtHr: Waist-to-Hip ratio.
} 


\section{Acknowledgements}

We thank Pep Castarlenas, manager of Ekke sport for his implications and help to the project.Thanks to Isabel del Arco, Divina Farreny and M.Luisa Guitard, for their participation in the qualitative validation of the educational resources (Participant's guide).

\section{Funding}

The study has been peer-reviewed (blinded) and quoted (6.4/7) by the AGAUR (Agency for Management of University and Research Grants) of the government of Catalonia (Generalitat de Catalonia). GE has been granted for hers' participation to the study as a PhD student. (Ref: 2014-PINEF-00003. PRE/2448/2014, de 30 October, DOGC num 6743-5.11.2014). This funding source had no role in the design of this study and will not have any role during its execution, analyses or interpretation of the data.

The study is mainly supported by the National Institute of Physical Education (INEFC)-Centre de Lleida. The funding covers central organisation, design, management, assessments, and analysis and reporting of the study. INEFC has also provided funding's to support the printing of educational resources (Funding's to research-2015) and partially blood analysis reagents (Funding's to research-2016)

The Catalonian Health Institute (ICS) provides the setting for the counselling sessions and supports recruitment, phlebotomy and general blood analysis. Ekke's sport centre (local sport centre) provides the setting and the necessary equipment for the physical exercise sessions.

The department of Experimental Medicine of the University of Lleida supports blood specimens' storage and metabolomics/lipidomics and miRNA blood analysis.

The Primary Care Research Institute (IDIAP) Jordi Gol provides support for the randomization and statistical analysis of data.

The Development of Healthy Organizations and Territories (DOTS) group of the University of LLeida and the Diputació de Lleida provided funding's to support partially miRNA blood analysis and the execution of physical activity sessions (Funding to research 25-07-2016).

\section{Availability of data and materials}

The datasets used during the current study will be available from the corresponding author on reasonable request.

\section{Author's contributions}

$A E, J S, G G, A B, J R M$ and NS conceived of the study. AE, GE, LM, FV and JS set up the study design. GE, RR, NS and FV designed the counselling intervention and $A E, A B, L M$ and $F V$ designed the supervised physical exercise sessions. JS and XS provided dietary habits expertise. GE, MM, GG, SS and JRM established recruitment strategies. JRM provided statistical expertise. AE leaded the drafting of the study protocol. All authors contributed to refinement of the study protocol draft and approved the final manuscript.

\section{Author's information}

The research team includes academic professionals with expertise in the fields of sports sciences ( $A B, L M, F V, N S)$, exercise physiology ( $A E)$, nutrition $(J S, X S)$, biochemistry (JS, AE), behaviour change strategies (RR, GE) and biostatistics (JRM) as well as clinicians (physicians and nurses) working at primary care centres (MM, GG, SS).

$\mathrm{AE}$ and GE are members of the Complex Systems in Sports Sciences research group (SGR 975).

\section{Competing interests}

The authors declare that they have no competing interests.

\section{Consent for publication}

Not applicable. No individual data will be published.

\section{Ethics approval and consent to participate}

This protocol and the template of the informed consent document were reviewed and approved (P15/122) by the Ethics Committee of the Primary Care Research Institute (IDIAP) Jordi Gol on the 22nd January 2016. Any modification to the protocol which may impact on the conduct of the study will require a formal amendment of the study. Such amendment will be agreed upon by the research group and approved by the above mentioned Ethics Committee.
Written informed consent will be obtained from all participants prior to their inclusion in the study.

\section{Received: 17 December 2016 Accepted: 23 February 2017 Published online: 14 March 2017}

\section{References}

1. Marcuello C, Calle-Pascual A, Fuentes M, Runkle I, Rubio M, Montañez C, et al. Prevalence of the metabolic syndrome in Spain using regional cutoff points for waist circumference; the di@bet.es study. Acta Diabetol. 2013;50: 615-623.

2. Bayley A, de Zoysa N, Cook DG, Whincup PH, Stahl D, Twist C, et al. Comparing the effectiveness of an enhanced MOtivational intErviwing InTervention (MOVE IT) with usual care for reducing cardiovascular risk in high risk subjects: study protocol for a randomised controlled trial. Trials. 2015;16:112

3. WHO. Global strategy on diet, physical activity and health. Geneva: WHO; 2004.

4. European Commission. Special Eurobarometer 412 - Sport and physical activity. Conducted by TNS opinion \& social. Brussels: European Commission; 2010

5. Pedersen BK, Saltin B. Exercise as medicine - evidence for prescribing exercise as therapy in 26 different chronic diseases. Scand J Med Sci Sports. 2015;25:1-72

6. Pattyn N, Cornelissen V, Eshghi RT, Vanhees L. The effect of exercise on the cardiovascular risk factors constituting the metabolic syndrome. Sports Med. 2013:43:121-33.

7. American College of Sports Medicine. ACSM's guidelines for exercise testing and prescription. 8th ed. Baltimore (MD): Lippincot Williams \& Wilkins; 2010.

8. Warbuton D, Charlesworth S, Ivey A, Nettlefold L, Bredin S. A systematic review of the evidence for Canada's physical activity guidelines for adults. International Journal of Behavioral Nutrition and Physical Activity. 2010;7:39.

9. WHO. Global recommendations on physical activity for health. Geneva: WHO Press; 2010.

10. Rankin A, Rankin A, Maclntyre P, Hillis W. Walk or run? Is high-intensity exercise more effective than moderate intensity exercise at reducing cardiovascular risk? Scott Med J. 2012;57:99-102.

11. Pattyn N, Coeckelberghs E, Buys R, Cornelissen V, Vanhees L. Aerobic interval training vs moderate continous training in coronary artery disease patients: a systematic reviwe and meta-analysis. Sports Med. 2014;44:687-700.

12. Arena R, Myers J, Forman D, Lavie C, Guazzi M. Should high-intensity interval training become the clinical standard in heart failure? Heart Failure Reviews. 2013;18:95-105.

13. Billat LV. Interval training for performance: a scientific and empirical practice. Special recommendations for middle- and long-distance running. Part I: aerobic interval training. Sports Med. 2001;31:13-31.

14. Helgerud J, Hoydal K, Wang E, Karlsen T, Berg P, Bjerkaas M, et al. Aerobic high-intensity intervals improve VO2max more than moderate training. Med Sci Sports Exerc. 2007;39:665-71.

15. Moholdt TT, Amundsen BH, Rustad LA, Wahba A, Lovo KT, Gullikstad LR, et al. Aerobic interval training versus continuous moderate exercise after coronary artery bypass surgery: a randomized study of cardiovascular effects and quality of life. Am Heart J. 2009;158:1031-7.

16. Rognmo O, Hetland E, Helgerud J, Hoff J, Slordahl SA. High intensity aerobic interval exercise is superior to moderate intensity exercise for increasing aerobic capacity in patients with coronary artery disease. Eur J Cardiovasc Prev Rehabil. 2004;11:216-22.

17. Wisloff U, Stoylen A, Loennechen JP, Bruvold M, Rognmo O, Haram PM, et al. Superior cardiovascular effect of aerobic interval training versus moderate continuous training in heart failure patients: a randomized study. Circulation. 2007;115:3086-94.

18. Stensvold D, Tjonna AE, Skaug EA, Aspenes S, Stolen T, Wisloff U, et al. Strength training versus aerobic interval training to modify risk factors of metabolic syndrome. J Appl Physiol (1985). 2010;108:804-10.

19. Tjonna AE, Stolen TO, Bye A, Volden M, Slordahl SA, Odegard R, et al. Aerobic interval training reduces cardiovascular risk factors more than a multitreatment approach in overweight adolescents. Clin Sci (Lond). 2009;116:317-26.

20. Tjonna AE, Lee SJ, Rognmo O, Stolen TO, Bye A, Haram PM, et al. Aerobic interval training versus continuous moderate exercise as a treatment for the metabolic syndrome: a pilot study. Circulation. 2008;118:346-54. 
21. Biddle S, Batterham A. High-intensity interval exercise training for public health: a big HIT or shall we HIT it on the head? International Journal of Behavioral Nutrition and Physical Activity. 2015;12:95

22. Morton JP, Kayani AC, McArdle A, Drust B. The exercise-induced stress response of skeletal muscle, with specific emphasis on humans. Sports Medicine. 2009:39:643-62.

23. Barlett J, Close G, MacLaren D, Gregson W, Drust B, Morton JP. High-intensity interval running is perceived as more enjoyable than moderate-intensity continuous exercise: implications for exercise adherence. J Sports Sci. 2011;29:547-53

24. Schulz K, Altman D, Moher D, Group TC. CONSORT 2010 Statement: updated guidelines for reporting parallel group randomised trials. BMC Med. 2010;8:18

25. Espigares G, Ensenyat A. Guia per a la promoció d'un estil de vida saludable. Lleida: INEFC; 2015.

26. Prochaska JO, DiClemente CC. Stages and processes of self-change of smoking: Toward an integrative model of change. J Consult Clin Psychol. 1983;51:390-5.

27. Miller W, Rollnick S. Motivational interviewing: helping people change. 3rd ed. New York: Guilford Press; 2013.

28. Landeta J. El método Delphi. Barcelona: Ariel; 2000.

29. Bernier M. Establishing the psycometric properties of a scale for evaluating quality in printed educatioin materials. Berner Institutional Design Scale. Educ Couns. 1996;29:283-99.

30. Doak C, Doak L, Root J. Assessing suitability of materials. In Doak C, Doak L, Root J. Teaching Patients with Low Literacy Skills. Philadelphia: Lippincott; 1996. p. 41-59.

31. Barrio-Cantalejo I. Los métodos de medición legibilidad y su aplicación al diseño de folletos educativos sobre salud. 2009.

32. Suni J, Husu P, Rinne M. Fitness for Health: The ALPHA-FIT test battery for adults aged 18-69. Tampere: European Union,DG SANCO, UKK Institute for Health Promotion Research; 2006

33. WHO. Waist circumference and waist-to-hip ratio: report of a WHO expert consultation. Edited by WHO. December 2008. 2011. Geneva. 8-11.

34. Pickering TG, Hall JE, Appel LJ, Falkner BE, Graves J, Hill MN, et al. Recommendations for blood pressure measurements in humans and experimental animals: part 1: Blood pressure measurements in humans: a statment for professionals from the subcommittee of professional and public education of the american heart associatioin council on high blood pressure research. Circulation. 2005;111:697-716.

35. Wijndaele K, Beunen G, Duvigneaud N, Matton L, Duquet W, Thomis M, et al. A continuous metabolic syndrome risk score: utility for epidemiological analyses. Diabetes Care. 2006;29:2329.

36. Expert panel on detection evaluation and treatment of high blood cholesterol in adults: Executive summary of the third report of the national cholesterol education programme (NCEP). JAMA 2001, 285: 2486-2497.

37. Amato M, Giordano C, Galia M, Criscimanna A, Vitabile S, Miridi M, et al. Visceral adiposity index. A reliable indicator of visceral fat function associated with cardiometabolic risk. Diabetes Care. 2010;33:920-2.

38. Frolkis A, Knox C, Lim E, Jewison T, Law V, Hau D, et al. SMPDB: The Small Molecules Pathway Database. Nucleic Acids Res. 2010;38:D480-487.

39. Jewison T, Su Y, Disfany F, Knox C, Maciejewski A, Poelzer J, et al. SMPDB 2.0: Big Improvements to Small Molecule Pathway Database. Nucleic Acids Res. 2014:42:D478-484.

40. Xia Lab. MetaboAnalyst 3.0 - a comprehensive tool suite for metabolomic data analysis. 2016. http://www.metaboanalyst.ca. Accessed 26 Feb 2017.

41. TMIC. Small Molecules Pathway Database. 2016. http://smpdb.ca. Accessed 26 Feb 2017.

42. Dunbar CC, Saul B. ECG interpretation for the clinical exercise physiologist. Baltimore (MD): Lippincott Williams \& Wilkins; 2009.

43. Borg G. Borg's perceived exertion and pain scales. Champaign, IL: Human Kinetics Publishers; 1998.

44. Troiano R, Berrigan D, Dodd K, Masse L, Tilert T, McDowel M. Physical activity in the United States measured by accelerometer. Med Sci Sports Exerc. 2008;40:181-8.

45. Martin-Moreno JM, Boyle P, Gorgojo L, Maisonneuve P, FernándezRodriguez JC, Savini S. Development and validation of a food frequency questionnaire in Spain. Int J Epidemiol. 1993;22:512-9.

46. González-Solanellas M, Romagosa M, Pérez-Portabella A, Zabaleta-del-Olmo E, Grau-Carod M, Casellas-Montagut C, et al. Estudio de prevalencia sobre hábitos alimentarios y estado nutricional en población adulta atendida en atención primaria. Nutr Hosp. 2011;26:337-44.

47. Bowman SA, Lino M, Gerrior SA, Basiotis PP. The healthy eating index: 1994-96. In Family Economics and Nutrition Review. Washington DC: U.S Department of Agriculture, Center for Nutrition Policy and Promotion; 1988. p. 2-14.

48. Basiotis PP, Carlson A, Gerrior SA, Juan WY, Lino M. The Healthy Eating Index 1999-2000. Washington, DC: US Department of Agriculture, Center for Nutrition Policy and Promotion, 2002, CNPP-12.

49. Serrani D. Elders Health empowerment scale. Spanish adaptation and psychometric analysis. Columbia Médica. 2014;45:179-85.

50. Bandura A: Guide for constructing self-efficacy scales. In Self-efficacy beliefs of adolescents. Tampere: Informaton Age Publishing; 2006:307-337.

51. Badia X, Roser M, Montserrat S, Herdman M, Segura A. The spanish version of EuroQol: a description and its applications. European Quality of Life scale. Med Clin (Barc). 1998:112:79-85.

52. Frew EJ, Bhatti $M$, Win $K$, Sitch $A$, Lyon A, Pallan $M$, et al. Cost-effectiveness of a community-based physical activity programme for adults (Be active) in UK: an economic analysis within a natural experiment. Br J Sports Med. 2014;48:207-12

53. Kendzierski D, DeCarlo K. Physical activity enjoyment scale: two validation studies. Journal of Sport Psychology. 1991;13:50-64.

54. Cohen J. A power primer. Psychological Bulletin. 1992;112:155-9.

55. WHO. 2008-2013 action plan for the global strategy for the prevention and control of non-communicable diseases: prevent and control cardiovascular diseases, cancers, chronic respiratory diseases and diabetes. Edited by WHO Document production services. Geneva: WHO Document production services; 2008

56. Myers J, Prakash M, Frelicher V, Do D. Exercise capacity and mortality among men referred for exercise testing. N Engl J Med. 2002;346:793-9.

57. de Souto BP. Why are we failing to promote physical activity globally? Bull World Health Organ. 2013;91:390-390A.

58. Biddle S, Brehm W, Verheijden M, Hopman-Rock M. Population physical activity behaviour change: a review for the European College of Sport Science. European Journal of Sport Science. 2012;12:367-83.

59. Fischer CP, Berntsen A, Perstrup LB, Eskildsen P, Pedersen BK. Plasma levels of interleukin- 6 and C-reactive protein are associated with physical inactivity independent of obesity. Scand J Med Sci Sports. 2007;17:580-7.

60. Marrugat J, Vila J, Baena-Díez JM, Grau M, Sala J, Ramos R, et al. Validez relativa de la estimación del riesgo cardiovascular a 10 años en una cohorte poblacional del estudio REGICOR. Rev Esp Cardiol. 2011;64:385-94.

\section{Submit your next manuscript to BioMed Central and we will help you at every step:}

- We accept pre-submission inquiries

- Our selector tool helps you to find the most relevant journal

- We provide round the clock customer support

- Convenient online submission

- Thorough peer review

- Inclusion in PubMed and all major indexing services

- Maximum visibility for your research

Submit your manuscript at www.biomedcentral.com/submit
Biomed Central 